\section{Commentary: The best is yet}

\section{to come}

\author{
Keith A. Dufendach, MD, and Danny Chu, MD ${ }^{\mathrm{a}, \mathrm{b}}$
}

Novel oral anticoagulants (NOAC) to prevent thromboembolic disease following valve surgery are an attractive alternative to vitamin $\mathrm{K}$ antagonists such as warfarin due to ease of dosing and no need for monitoring anticoagulation levels. Shim and colleagues ${ }^{1}$ presented the results of the Explore the Efficacy and Safety of Edoxaban in Patients after Heart Valve Repair or Bioprosthetic Valve Replacement randomized clinical trial comparing the safety and efficacy of edoxaban and warfarin in 218 patients following bioprosthetic valve replacement or valve repair. After 12 weeks, there were 4 thromboembolic events in the warfarin group $(3.7 \%)$, and none in the edoxaban group. One patient in the warfarin group $(0.9 \%)$ experienced major bleed during follow-up and 3 in the edoxaban group $(2.8 \%)$. These results were deemed noninferior according to the investigative team's prespecified noninferiority criteria.

These results are important and represent an early step toward the approved use of NOACs following valve surgery. Recent American College of Cardiology/American Heart Association and European Society of Cardiology/European Association for Cardio-Thoracic Surgery guidelines recommend anticoagulation with warfarin or other vitamin $\mathrm{K}$ antagonists for the first 3 months following bioprosthetic valve replacement or valve repair in patients with at least 1 additional indication for anticoagulation. ${ }^{2,3}$ However, the challenge of maintaining a therapeutic international

From the a Division of Cardiac Surgery, Department of Cardiothoracic Surgery, University of Pittsburgh School of Medicine, Pittsburgh, Pa; and ${ }^{\mathrm{b}} \mathrm{Heart}$ and Vascular Institute, University of Pittsburgh Medical Center, Pittsburgh, Pa.

Disclosures: Dr Chu has acted as an international proctor/consultant for the Japanese Organization for Medical Device Development, Inc, is on the faculty for The Osler Institute, and is a journal editor for Wolters Kluwer Health. Dr Dufendach reported no conflicts of interest.

The Journal policy requires editors and reviewers to disclose conflicts of interest and to decline handling or reviewing manuscripts for which they may have a conflict of interest. The editors and reviewers of this article have no conflicts of interest.

Received for publication Feb 8, 2021; revisions received Feb 8, 2021; accepted for publication Feb 8, 2021; available ahead of print Feb 17, 2021.

Address for reprints: Danny Chu, MD, Division of Cardiac Surgery, Department of Cardiothoracic Surgery, University of Pittsburgh School of Medicine, 200 Lothrop St, Suite C-700, Pittsburgh, PA 15213 (E-mail: chud@upmc.edu).

J Thorac Cardiovasc Surg 2023;165:68-9

0022-5223/ $\$ 36.00$

Copyright (C) 2021 by The American Association for Thoracic Surgery

https://doi.org/10.1016/j.jtcvs.2021.02.028

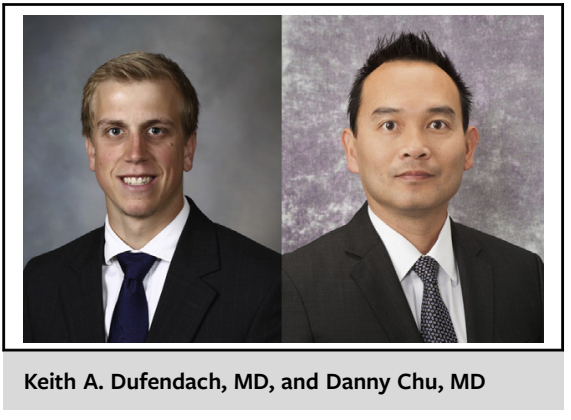

CENTRAL MESSAGE

Edoxaban has similar efficacy and safety to warfarin following valve repair or bioprosthetic replacement, but underwhelming outcome event rates should temper enthusiasm.

normalized ratio with warfarin are well recognized, as demonstrated by patients taking warfarin spending just $53.4 \%$ of the study period in the therapeutic international normalized ratio range of 2.0 to 3.0 in the present trial. ${ }^{1}$ This stands in stark contrast to the significantly higher rates of medication compliance, and therefore therapeutic anticoagulation, in the edoxaban group. ${ }^{1}$

However, notable limitations to the trial ${ }^{1}$ should temper enthusiasm for supplanting the use of warfarin with edoxaban in these patients. In particular, lower than expected rates of the primary efficacy outcome and low rates of both primary and secondary safety outcomes raises concern that a clinically significant difference in efficacy may have been missed for both safety and efficacy. Additionally, only $61 \%$ of patients in the study had documented atrial fibrillation at time of randomization postoperatively, and anticoagulation is controversial in patients with bioprosthetic valve replacement or valve repair without a secondary indication for anticoagulation. ${ }^{1,2,4}$ Although these concerns are appropriately acknowledged by the authors of the study, additional studies will be necessary before changing practice guidelines.

Lastly, and perhaps most interestingly, the results of this study may generate increased interest in NOAC use for populations undergoing transcatheter valve implantation. With the stunning rise in rates of transcatheter aortic valve implantation and the ongoing development of catheter-based mitral valve replacement techniques, development of the ideal postimplantation antithrombotic regimen is essential because 
thrombus formation continues to be a problem in these patients despite use of dual antiplatelet therapy., ${ }^{2,5}$ Although transcatheter valves were explicitly excluded from the present study, ${ }^{1}$ a well-designed and thoughtful trial considering the use of NOAC versus warfarin in patients following transcatheter valve implantation is perhaps warranted.

\section{References}

1. Shim SY, Seo J, Kim YK, Kim YJ, Lee SH, De Catereina R, et al. Efficacy and safety of edoxaban in patients early after surgical bioprosthetic valve implantation or valve repair: a randomized clinical trial. J Thorac Cardiovasc Surg. 2023; 165:58-67.e4.
2. Otto CM, Nishimura RA, Bonow RO, Carabello BA, Erwin JP, Gentile F, et al $2020 \mathrm{ACC} / \mathrm{AHA}$ guideline for the management of patients with valvular heart disease: executive summary: a report of the American College of Cardiology/American Heart Association joint committee on clinical practice guidelines. Circulation. 2021;143:e35-71.

3. Baumgartner H, Falk V, Bax JJ, De Bonis M, Hamm C, Holm PJ, et al. 2017 ESC/ EACTS guidelines for the management of valvular heart disease. Eur Heart $J$. 2017;38:2739-86

4. ElBardissi AW, DiBardino DJ, Chen FY, Yamashita MH, Cohn LH. Is early antithrombotic therapy necessary in patients with bioprosthetic aortic valves in normal sinus rhythm? J Thorac Cardiovasc Surg. 2010;139:1137-45.

5. Chakravarty T, Patel A, Kapadia S, Raschpichler M, Smalling RW, Szeto WY et al. Anticoagulation after surgical or transcatheter bioprosthetic aortic valve replacement. J Am Coll Cardiol. 2019;74:1190-200.
See Article page 58.

\section{Commentary: Battle of the bioprosthetic valve blood thinners}

\author{
Ahmed Alnajar, MD, ${ }^{a}$ J. Sunil Rao, $\mathrm{PhD},{ }^{\mathrm{b}}$ \\ Shari Messinger Cayetano, $\mathrm{PhD},{ }^{\mathrm{b}}$ and \\ Joseph Lamelas, MD
}

Shim and colleagues ${ }^{1}$ present a prospective, nonblinded, randomized control trial of 218 patients who either received edoxaban or warfarin following surgical bioprosthetic valve replacement or valve repair. Their results are impressive, and more importantly, because there is an unmet clinical need for an alternative to warfarin, their message of edoxaban's noninferiority is timely and essential.

Warfarin inhibits the production of several coagulation factors. Despite its narrow therapeutic window, dietary interactions, and adherence issues, it has long been the only option for long-term oral anticoagulation. Additionally, some patients may be genetically hyper- or hyporesponsive to warfarin, which poses difficulties in the postoperative management. On the other hand, promising alternatives to

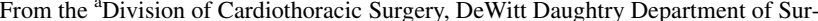
gery, University of Miami Miller School of Medicine, Miami, Fla; and the bivision of Biostatistics, Department of Public Health Sciences, University of Miami Miller School of Medicine, Miami, Fla.

Disclosures: The authors reported no conflicts of interest.

The Journal policy requires editors and reviewers to disclose conflicts of interest and to decline handling or reviewing manuscripts for which they may have a conflict of interest. The editors and reviewers of this article have no conflicts of interest.

Received for publication Feb 12, 2021; revisions received Feb 12, 2021; accepted for publication Feb 17, 2021; available ahead of print Feb 22, 2021.

Address for reprints: Ahmed Alnajar, MD, Division of Cardiothoracic Surgery, DeWitt Daughtry Department of Surgery, University of Miami, 1295 NW 14th St, South Building, Suite J, Miami, FL 33125 (E-mail: alnajarmd@gmail.com).

J Thorac Cardiovasc Surg 2023;165:69-70

$0022-5223 / \$ 36.00$

Copyright (C) 2021 by The American Association for Thoracic Surgery

https://doi.org/10.1016/j.jtcvs.2021.02.064
}

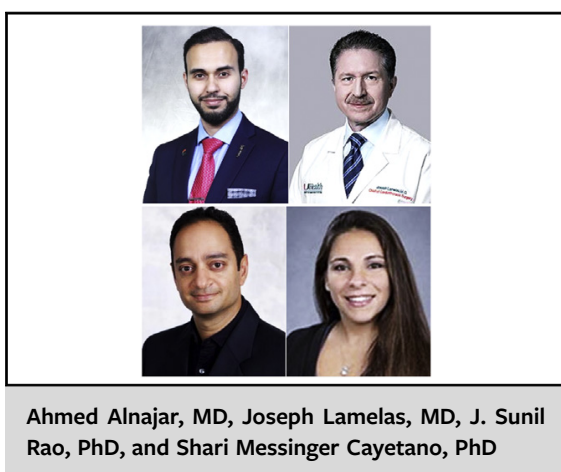

CENTRAL MESSAGE

The clinical significance of

postoperative thrombotic events necessitates choosing the

optimal blood thinners in

patients undergoing valvular

surgery to improve cardiac

surgery care and outcomes.

warfarin such as direct oral anticoagulants-inhibit activated factor $\mathrm{X}$-have shown noninferiority and significantly less bleeding compared with warfarin. ${ }^{2}$ Furthermore, they have shown superiority in preventing stroke and systemic embolism. ${ }^{3}$ However, they are still limited in their use for nonvalvular atrial fibrillation.

The optimal anticoagulation therapy following valvular surgery is still a matter of debate due to limited evidence. ${ }^{4}$ An appealing rationale for perioperative anticoagulation includes minimizing thrombus formation on the bioprosthetic valve and suture material that has not undergone 